\title{
Optical gain measurements in porous silicon planar waveguides codoped by erbium and ytterbium ions at $1.53 \mu \mathrm{m}$
}

\author{
Adel Najar, Joël Charrier, ${ }^{a)}$ Nathalie Lorrain, and Lazhar Haji \\ Laboratoire d'Optronique, FOTON CNRS-UMR 6082, Université de Rennes 1, ENSSAT Technopole \\ Anticipa, 6 rue de Kérampont, BP 80518-22305 Lannion Cedex, France \\ Mehrezi Oueslati \\ Laboratoire de Spectroscopie Raman, Faculté des Sciences de Tunis, 2092 ElManar, Tunis, Tunisia
}

(Received 22 May 2007; accepted 31 August 2007; published online 21 September 2007)

\begin{abstract}
The on-off optical gain measurements as a function of the pump power were performed on porous silicon planar waveguides codoped by erbium and ytterbium ions. These measurements were obtained for different ratios of $\mathrm{Yb}$ concentration to Er concentration. The highest value of the gain was reached when the $\mathrm{Yb}$ concentration is three times higher than that of $\mathrm{Er}$ at a moderate $980 \mathrm{~nm}$ pump power value equal to $70 \mathrm{~mW}$. Optical losses measurements have been performed on these waveguides and were equal to $2.1 \mathrm{~dB} / \mathrm{cm}$ and an internal gain of about $6.4 \mathrm{~dB} / \mathrm{cm}$ was obtained. () 2007 American Institute of Physics. [DOI: 10.1063/1.2789185]
\end{abstract}

Er doped materials are of great interest in optical communications technology as they can be used as erbium doped waveguide amplifiers to provide an optical gain over short propagation distances at the standard telecommunication wavelength of $1.5 \mu \mathrm{m}$. They can be used to compensate for coupling losses, waveguide losses, or the power division in optical splitter. All kinds of Er doped silicon nanostructures such as porous silicon, ${ }^{1,2} \mathrm{Si}$ nanocrystals embedded in $\mathrm{SiO}_{2}$ matrix, ${ }^{3,4}$ and $\mathrm{Si} / \mathrm{SiO}_{2}$ superlattices ${ }^{5,6}$ have been widely studied.

Among them, porous silicon (PS) was used as a host material for erbium (Er) atoms to obtain a high Er concentration [in the order of $10^{20} \mathrm{~cm}^{-3}$ (Refs. 7 and 8)] because of its high specific surface. The electrochemical method is usually used to obtain a homogeneous Er doping into porous silicon layer. ${ }^{9}$ The same method can also be used to incorporate ytterbium $(\mathrm{Yb})$. Thermal treatments are then necessary to diffuse and optically activate $\mathrm{Er}$ and $\mathrm{Yb}$ ions in order to observe rare earth luminescence. The $\mathrm{Yb}-\mathrm{Er}$ codoping permits to obtain luminescent structures from silicon with a high radiative efficiency by direct energy transfer from the excited state of $\mathrm{Yb}$ to the state of Er. ${ }^{10}$ Optical gain measurements have still not been reported in the PS waveguides doped by $\mathrm{Er}$ or $\mathrm{Er}-\mathrm{Yb}$ ions.

In this letter, the on-off optical gain was studied as a function of the pump power for different doping $[\mathrm{Yb}] /[\mathrm{Er}]$ ratios performed on PS planar waveguides. The internal optical gain at $1.53 \mu \mathrm{m}$ was then deduced. These results have permitted to optimize the $\mathrm{Yb}$ concentration incorporation in comparison with Er concentration to obtain a waveguide amplifier.

Porous silicon planar waveguides were prepared by electrochemical etching of a (100)-oriented heavily doped (4-6 $\mathrm{m} \Omega \mathrm{cm}$ resistivity) $P^{+}$-type silicon substrate. The electrolyte was made by mixing $\mathrm{HF}(50 \%)$, ethanol, and $\mathrm{H}_{2} \mathrm{O}$ (2:2:1). Two-layer (a guiding and a cladding layer) planar waveguides were formed by applying current densities of 50 and $80 \mathrm{~mA} / \mathrm{cm}^{2}$, respectively. The thickness of the guiding layer was set to $3 \mu \mathrm{m}$ and that of the cladding layer was

\footnotetext{
${ }^{a)}$ Electronic mail: joel.charrier@enssat.fr
}

$5 \mu \mathrm{m}$ to avoid the radiating mode from the silicon substrate.

Then, the Er and $\mathrm{Yb}$ ions were electrochemically deposited onto the porous silicon waveguides (PSWGs) at a constant current density of $0.1 \mathrm{~mA} / \mathrm{cm}^{2}$ for $10 \mathrm{~min}$. The $\mathrm{Er}-\mathrm{Yb}$ ions solutions were prepared by varying $\mathrm{Yb}$ concentrations whereas the Er concentration was kept constant. The term $\tau$ corresponds to the ratio of the $\mathrm{Yb}$ concentration to the one of Er in solution. Different values of $\tau$ were carried out ( $\tau=1,2$, 3 , or 5). Thermal treatments for ion diffusion and optical activation were performed on the codoped PSWG using a three-step process. First, the structure of PSWG was stabilized by a preoxidation at low temperature $\left(300{ }^{\circ} \mathrm{C}\right)$ in wet $\mathrm{O}_{2}$, and then the PSWGs were oxidized at $900{ }^{\circ} \mathrm{C}$ in wet $\mathrm{O}_{2}$. Lastly, the temperature was raised to $1000{ }^{\circ} \mathrm{C}$ in $\mathrm{N}_{2}$ gas to diffuse and to activate the rare earth ions. The samples were annealed in $\mathrm{O}_{2}$ to oxidize the silicon skeleton and thus to convert them into porous silica. ${ }^{11}$ The refractive indices of the guiding and cladding layers decreased after oxidation from 1.78 and 1.53 (before codoping and oxidation) down to 1.33 and 1.31, respectively. ${ }^{12}$ Moreover, the Er and $\mathrm{Yb}$ concentrations in the layers were estimated by energy dispersive $\mathrm{x}$-ray (EDX) analysis performed on the sample cross section. The concentration profiles were homogeneous in depth and their values are reported in Table I and confirm the ratio between $\mathrm{Er}$ and $\mathrm{Yb}$ concentrations incorporated in the different samples.

Gain measurements performed on these waveguides were characterized with a pump at $980 \mathrm{~nm}$ and a signal at $1530 \mathrm{~nm}$. The source which was used for the pump is a $980 \mathrm{~nm} \lambda$ Highwave $C$ band erbium doped fiber broading source. A tunable laser system operating between 1470 and

TABLE I. Er and $\mathrm{Yb}$ concentrations determined by EDX analysis performed on the sample cross section as a function of the ratio $(\tau)$ of $\mathrm{Yb}$ concentration to Er concentration in solution.

\begin{tabular}{ccccc}
\hline \hline $\begin{array}{c}\text { Type of } \\
\text { waveguides }\end{array}$ & $\tau=1$ & $\tau=2$ & $\tau=3$ & $\tau=5$ \\
\hline$[\mathrm{Er}] 10^{20} \mathrm{~cm}^{-3}$ & 2.8 & 1.4 & 1.1 & 0.9 \\
{$[\mathrm{Yb}] 10^{20} \mathrm{~cm}^{-3}$} & 2.8 & 3 & 3.5 & 3.8 \\
\hline \hline
\end{tabular}




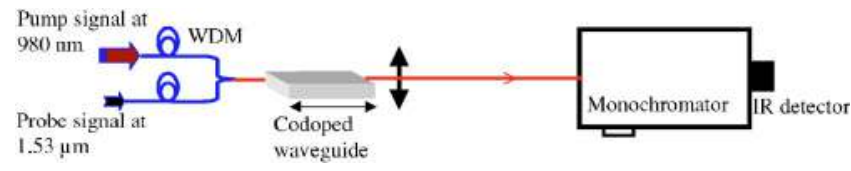

FIG. 1. (Color online) Experimental setup for gain measurements [wavelength-division multiplexer (WDM): 980/1550 nm].

$1565 \mathrm{~nm}$ (Agilent 81680A) with a resolution of $0.001 \mathrm{~nm}$ was used as a probe signal at $1530 \mathrm{~nm}$. To increase the fiber to waveguide coupling efficiency at the input face of the sample, a lens fiber with a $4 \mu \mathrm{m}$ mode field diameter was used. Both pump and probe signals were coupled by using an output 980/1550 wavelength-division multiplexer coupler. The end-face guided light was collected with a microscope objective and was imaged into a monochromator interfaced with an IR digital camera which was allowed single spot measurements as a function of a fixed wavelength (Fig. 1). The IR digital camera response is constant in the used range of wavelength. The intensity of the light spot was recorded with a digital camera by integrating the values of pixel corresponding to the spot. All the spectra (output signals) were collected as a function of the wavelength and all the measurements were performed at a fixed wavelength with $11 \mathrm{~nm}$ resolution. Moreover, propagation losses were measured by studying the scattered light from the surface of the waveguide $^{13,14}$ at near IR range.

On-off gain was determined from the ratio of the output signal as measured by the IR digital camera when both the pump and probe beams were coupled to the PS waveguide to the output signal in the absence of the pump. We had well checked well that this output signal is not due to amplified spontaneous emission (ASE) phenomena by measuring the intensity of the ASE that is not significant (without incoming signal).

The on-off gain measurements as a function of the pump power are reported in Fig. 2 for different $\tau$ values. For a given $\tau$, the gain increases with the pump power and begins to saturate. Firstly, for the low pump powers ( $P_{\text {pump }}$ $<50 \mathrm{~mW}$ ), on-off gain values increase slightly for the different codoping ratios. Then the gain values increase faster. This evolution is due to the variation of the absorption cross section of $\mathrm{Yb}$ ions at $980 \mathrm{~nm}$. Lastly, for the high pump powers $\left(P_{\text {pump }}>50 \mathrm{~mW}\right)$, the gain values slightly increase until saturation. However, the saturation value $\left(g_{\text {sat }}\right)$ depends on the $\tau$ value. The $g_{\text {sat }}$ value increases when $\tau$ varies from 1 to 3 and strongly decreases for $\tau=5$. These values are in good agreement with the observed results by photoluminescence performed on codoped waveguides. ${ }^{15}$ This increase in on-off gain with the one of $\mathrm{Yb}$ concentration is related to the enhanced direct energy transfer from $\mathrm{Yb}$ excited states to the $I_{13 / 2}$ state of Er. The highest value was reached for $\tau=3$ at a power pump equal to $70 \mathrm{~mW}$. The thermal oxidation of porous layers and the thermal treatment in $\mathrm{N}_{2}$ at $1000^{\circ} \mathrm{C}$ per-

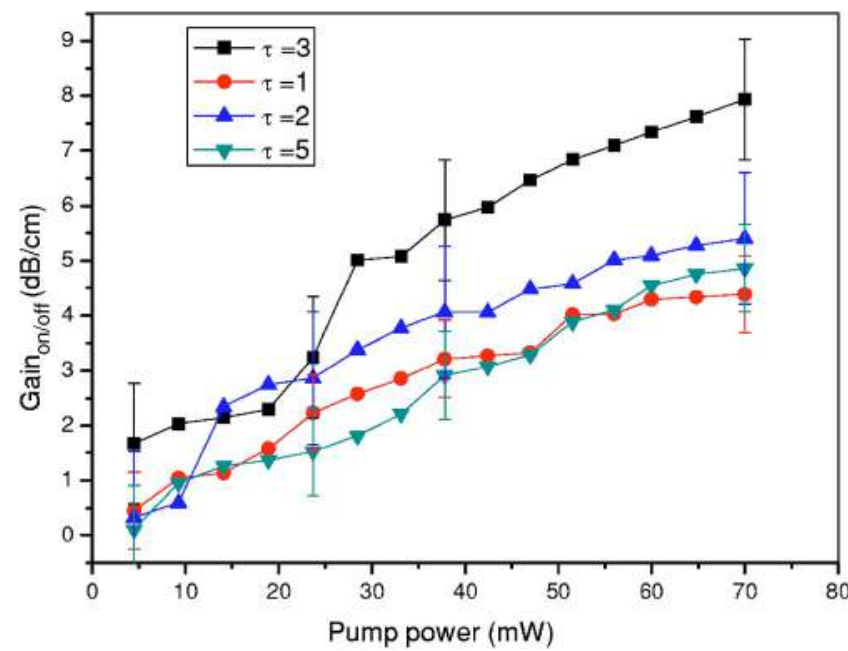

FIG. 2. (Color online) Experimental on-off gain at $1.53 \mu \mathrm{m}$ as a function of the pump power at $980 \mathrm{~nm}$ for the different ratios $(\tau)$ of $\mathrm{Yb}$ concentration to Er concentration. The input signal power is equal to $100 \mu \mathrm{W}$.

mit to diffuse and to activate the Er ions by forming active complexes such as $\mathrm{Si}-\mathrm{Er}-\mathrm{O}$. We think that up to $\tau=3$, the quantity of active complexes increases, increasing the gain by energy transfer from $\mathrm{Yb}$ ion to Er ion. For $\tau=5$, the gain decreases because the high concentration of $\mathrm{Yb}$ induces a strong interaction between neighbor ions of $\mathrm{Yb}$. So, a low radiative efficiency by direct energy transfer at $1.53 \mu \mathrm{m}$ is obtained.

From these on-off gains and from loss measurements, the internal gain for the codoped waveguides was inferred. The measurements of on-off gain have been performed for several lengths of sample for $\tau=3$. The mean value is equal to $8.5 \mathrm{~dB} / \mathrm{cm}$. The propagation losses were measured for the undoped waveguides and for the different codoped waveguides. These values are reported in Table II. The origins of the losses are principally due to surface scattering. ${ }^{16}$ The increase in losses after codoping is related to the presence of $\mathrm{Er}$ and $\mathrm{Yb}$ aggregates on the sample surface ${ }^{17}$ that increases the roughness interface, inducing additional losses and at $\mathrm{Er}-\mathrm{Yb}$ absorption.

The highest internal gain reached in this study was equal to $6.4 \mathrm{~dB} / \mathrm{cm}$ for $\tau=3$ obtained at a moderate pump power value of $70 \mathrm{~mW}$. Larger gain could be expected by achieving single mode buried waveguides at 980 and $1530 \mathrm{~nm}$ to obtain a better overlap rate.

In conclusion, we have manufactured erbium-ytterbium codoped PS waveguides and evidenced their ability to be used as a light amplifier around the wavelength equal to $1.5 \mu \mathrm{m}$. Higher gain values can be expected by achieving single mode buried waveguides and by achieving waveguides at low temperature to obtain good quality interfaces and so reduce surface scattering losses due to the interface roughness.

TABLE II. Loss values of undoped waveguides and $\mathrm{Er}-\mathrm{Yb}$ codoped waveguides as a function of the ratio $(\tau)$ of $\mathrm{Yb}$ concentration to Er concentration at $1.55 \mu \mathrm{m}$.

\begin{tabular}{cccccc}
\hline \hline \multirow{2}{*}{$\begin{array}{c}\text { Type of } \\
\text { waveguides }\end{array}$} & Undoped & $\tau=1$ & $\tau=2$ & $\tau=3$ & $\tau=5$ \\
\cline { 3 - 6 } & $0.7 \pm 0.3$ & $1.7 \pm 0.5$ & $1.9 \pm 0.7$ & $2.1 \pm 0.8$ & $1.9 \pm 0.8$ \\
\hline Losses $(\mathrm{dB} / \mathrm{cm})$ & & \multicolumn{4}{c}{ Codoped } \\
\hline \hline
\end{tabular}


${ }^{1}$ A. M. Dorofeev, N. V. Gaponenko, V. P. Bondarenko, E. E. Bachilo, N. M. Kazuchits, A. A. Leshok, G. N. Troyanova, N. N. Vorosov, V. E. Borisenko, H. Gnaser, W. Bock, P. Becker, and H. Oechsner, J. Appl. Phys. 77, 2679 (1995).

${ }^{2}$ X. Wu, U. Hömmerich, F. Namavar, and A. M. Cremins-Costa, Appl. Phys. Lett. 69, 1903 (1996).

${ }^{3}$ M. Fujii, M. Yoshida, S. Hayashi, and K. Yamamoto, J. Appl. Phys. 84, 1790 (1998).

${ }^{4}$ P. G. Kik and A. Polman, J. Appl. Phys. 91, 534 (2002).

${ }^{5}$ V. Vinciguerra, G. Franzò, F. Priolo, F. Iacona, and C. Spinella, J. Appl. Phys. 87, 8165 (2000).

${ }^{6}$ P. Photopoulos, A. G. Nassiopoulou, D. N. Kouvatsos, and A. Travlos, Appl. Phys. Lett. 76, 3588 (2000).

${ }^{7}$ L. Tsybeskov, S. P. Duttagupta, K. D. Hirschman, P. M. Fauchet, K. L. Moore, and D. G. Hall, Appl. Phys. Lett. 70, 1790 (1997).

${ }^{8}$ A. Najar, J. Charrier, H. Ajlani, N. Lorrain, H. Elhouichet, M. Oueslati, and L. Haji, J. Lumin. 121, 245 (2006).
${ }^{9}$ T. Kimura, A. Yokoi, H. Horiguchi, R. Saito, T. Ikoma, and A. Sato, Appl. Phys. Lett. 65, 983 (1994).

${ }^{10}$ V. V. Filippov and P. P. Pershukevich, J. Lumin. 99, 185 (2002).

${ }^{11}$ P. Pirasteh, J. Charrier, A. Soltani, S. Haesaert, L. Haji, C. Godon, and N. Errien, Appl. Surf. Sci. 253, 1999 (2006).

${ }^{12}$ A. Najar, H. Ajlani, J. Charrier, N. Lorrain, S. Haesaert, M. Oueslati, and L. Haji, Physica B 396, 145 (2007).

${ }^{13}$ Y. Okamura, S. Yoshinaka, and S. Yamamoto, Appl. Opt. 22, 3892 (1983).

${ }^{14}$ Y. Okamura, S. Sato, and S. Yamamoto, Appl. Opt. 24, 57 (1985).

${ }^{15}$ A. Najar, J. Charrier, H. Ajlani, N. Lorrain, H. Elhouichet, M. Oueslati, and L. Haji, "Optical gain at $1.53 \mathrm{~m}$ in $\mathrm{Er}^{3+}-\mathrm{Yb}^{3+}$ co-doped porous silicon waveguides," Mater. Sci. Eng., B (in press).

${ }^{16}$ P. Pirasteh, J. Charrier, Y. Dumeige, S. Haesaert, and P. Joubert, J. Appl. Phys. 101, 083110 (2007)

${ }^{17}$ P. Pirasteh, J. Charrier, Y. Dumeige, A. Chaillou, M. Guendouz, and L. Haji, Appl. Surf. Sci. 253, 3440 (2007). 